\title{
WORKSHOP PEMBELAJARAN MATEMATIKA ONLINE UNTUK SEKOLAH MENENGAH
}

\section{WORKSHOP OF MATHEMATICS ONLINE LEARNING FOR SECONDARY SCHOOL}

\author{
Retno Marsitin ${ }^{1 *}$, Nyamik Rahayu Sesanti ${ }^{2}$ \\ ${ }^{1}$ Pendidikan Matematika, Universitas PGRI Kanjuruhan Malang, Malang, JawaTimur \\ ${ }^{2}$ PGSD, Universitas PGRI Kanjuruhan Malang, Malang, Jawa Timur \\ *Email: mars_retno@unikama.ac.id
}

(Diterima 27-07-2021; Disetujui 23-08-2021)

\begin{abstract}
ABSTRAK
Era globalisasi pada masa pandemi covid-19 dengan pembelajaran daring menuntut guru untuk melek teknologi. Kompetensi guru dan kinerja dalam pembelajaran matematika sekolah menengah harus ditingkatkan agar pembelajaran lebih berkualitas. Guru yang belum memanfaat teknologi dalam pembelajaran masih ada, padahal sekarang di era revolusi industri 4.0 yang menuntut guru melakukan inovasi dalam pembelajaran. Solusi permasalahan tersebut dengan mengadakan serangkaian kegiatan pengabdian berupa pelatihan dan pendampingan penyusunan Rencana Pelaksanaan Pembelajaran dengan pendekatan dan model pembelajaran daring, pembuatan Lembar Kerja Peserta Didik materi matematika berbasis teknologi, pembuatan desain pembelajaran daring melalui aplikasi Learning Managemen System dengan menarik dan bervariasi, penggunaan aplikasi-aplikasi pembelajaran untuk pembelajaran matematika secara daring, merancang asesmen pembelajaran matematika berbantuan aplikasi-aplikasi pembelajaran. Metode yang ditempuh yaitu pelatihan, dan pendampingan serta diskusi dalam kegiatan pengabdian. Kelompok guru matematika terlibat aktif selama kegiatan berlangsung hingga berakhirnya kegiatan serta evaluasi. Kegiatan ini bertujuan untuk meningkatkan kualitas guru matematika sekolah menengah dalam aplikasi matematika untuk menyelesaikan permasalahan dalam matematika. Kegiatan pelatihan ini mendapatkan tanggapan dan respon yang baik dan positif. Hal ini terbukti dari hasil pelaksanaan kegiatan ini dapat ditunjukkan dengan produk dari para guru matematika berupa Rencana Pelaksanaan Pembelajaran Matematika sekolah menengah secara daring, Lembar Kerja Peserta Didik berbasis teknologi, desain pembelajaran matematika secara daring menggunakan aplikasi Learning Managemen system, dan asesmen pembelajaran matematika berbantuan aplikasi-aplikasi pembelajaran.
\end{abstract}

Kata kunci: pembelajaran daring, matematika sekolah menengah

\section{ABSTRACT}

The globalization era during the covid-19 pandemic with online learning requires teachers to be technology literate. Teachers' competence and performance on mathematics learning in high school must be improved thus the learning quality will be better. The teachers who have not utilized technology in learning are still exist, even though the era of industrial revolution 4.0 requires teachers to innovate in learning. The solution to these problems is by holding a series of service activities in the form of workshop and assistance in the preparation of Lesson Plans with online learning approaches and models, making Student Worksheets on technology-based mathematics materials, making online learning designs through interesting and varied Learning Management system applications, using various learning applications for online mathematics learning, designing mathematics learning assessments assisted by learning applications. The methods used are training, assisting, and discussion in this service activities. The group of mathematics teachers was actively involved during the activity until the end of the activity and evaluation. This activity aims to improve the quality of secondary school mathematics teachers on the mathematics application to solve problems in mathematics. This workshop activity received good and positive responses and feedbacks. This is proved from the results of the implementation of this activity, which can be demonstrated by the products of mathematics teachers in the form of online Mathematics lesson plan for high school, technology-based Student Worksheets, online mathematics learning designs using the Learning Management system application and mathematics learning assessments assisted by learning applications.

Keywords: online learning, high school mathematics 


\section{PENDAHULUAN}

Pembelajaran daring merupakan pembelajaran jarak jauh dengan memanfaatkan teknologi berupa komputer atau android sebagai solusi pembelajaran pada masa pandemi covid-19. Pada masa sekarang era globalisasi dengan covid-19, pembelajaran daring diterapkan pada sekolah menengah khususnya pembelajaran daring matematika. Pembelajaran daring matematika sekolah menengah memerlukan keterampilan khusus dalam aplikasi rumus matematika dengan berbagai lambang matematika. Berkenaan dengan hal tersebut, guru berperan penting untuk memiliki kemampuan teknologi agar dapat berinovasi dengan pembelajaran daring terutama pembelajaran daring matematika sekolah menengah.

Pemanfaatan teknologi dengan prinsip yaitu: meningkatkan kualitas pembelajaran matematika, mendukung pembelajaran secara lebih efektif dan memberi pengaruh tentang materi matematika yang diajarkan (Atteh et al., 2020; Cahyono \& Ludwig, 2019; NavarroIbarra et al., 2017). Pengalaman yang menyenangkan, apabila guru sebagai tenaga pendidik dalam menyampaikan materi matematika sebagai suatu aplikasi yang menarik adalah dengan mengakses internet dan menggunakan software matematika (Engelbrecht et al., 2020; Loong, 2014). Internet dan software komputer dapat digunakan sebagai alat pengajaran untuk mengeksplorasi, menyelidiki, menyelesaikan masalah, berinteraksi, merefleksi, bernalar, berkomunikasi, dan belajar banyak konsep yang sesuai kurikulum sekolah. Penyampaian materi berbentuk visual melalui teknologi komputer sangat penting, dengan syarat bahwa perancangan program secara terstruktur dan mudah dimengerti (Keengwe \& Georgina, 2012; Ruthven et al., 2009) menyatakan bahwa perkembangan teknologi memberikan perubahan terhadap pelaksanaan pengajaran dan pembelajaran. Pembelajaran daring bermanfaat untuk mengatasi permasalahan dan memudahkan untuk mengakses materi. Teknologi informasi dapat diterima sebagai media dalam proses pendidikan, termasuk membantu proses belajar mengajar, melibatkan pencarian referensi dan sumber informasi (Belo et al., 2016; Carter et al., 2020).

Kualitas guru secara keseluruhan berdampak langsung pada capaian kompetensi peserta didik. Guru harus terus belajar meningkatkan kompetensinya dalam konteks pembelajaran bermakna, sehingga dapat meningkatkan capaian kompetensi peserta didik dalam setiap aspek perilaku yang menjadi tujuan pembelajaran baik sikap, pengetahuan, maupun keterampilan. Tugas seorang guru memang kompleks dan harus memperhatikan keseimbangan antara mengajar dan belajar (Harris \& Sass, 2011; Toropova et al., 2019). 
Mencermati fenomena yang telah dipaparkan maka program kemitraan masyarakat memberikan solusi untuk mengatasi permasalahan diatas dengan melaksanakan kegiatan pengabdian dengan memberikan pelatihan pembalajaran daring matematika sekolah menengah. Adapun tujuan pelatihan pembelajaran daring matematika sekolah menegah yaitu untuk meningkatkan kualitas guru matematika sekolah menengah dalam aplikasi matematika untuk menyelesaikan permasalahan matematika

\section{BAHAN DAN METODE}

Metode dalam menyelesaikan permasalahan dengan menyelenggarakan pelatihan dan pendampingan bimbingan pembuatan materi matematika sekolah menengah berbasis teknologi, pembelajaran daring matematika dan media pembelajaran matematika. Selanjutnya, pembentukan diskusi yang aktif untuk mempersentasikan hasil produk materi matematika sekolah menengah berbasis teknologi, pembelajaran daring matematika sekolah menengah dan media pembelajaran matematika. Sebagai mitra kegiatan pengabdian yaitu kelompok guru matematika sekolah menengah yang memiliki kepedulian membimbing dan mendidik anak yatim piatu di wilayah Malang. Kegiatan pelatihan pembelajaran daring di Universitas PGRI Kanjuruhan Malang.

Langkah-langkah praktis sebagai solusi atas permasalahan mitra dalam kegiatan pengabdian yaitu: (a) Sosialisasi Rencana Pelaksanaan Pembelajaran dengan pendekatan dan model pembelajaran daring; (b) Sosialisasi Lembar Kerja Peserta Didik materi matematika berbasis teknologi; (c) Sosialisasi desain pembelajaran daring melalui aplikasi Learning Managemen System; (d) Sosialisasi aplikasi-aplikasi pembelajaran untuk pembelajaran matematika secara daring; (e) Sosialiasi merancang asesmen pembelajaran matematika berbantuan aplikasi-aplikasi pembelajaran; (f) Pelatihan dan pendampingan penyusunan Rencana Pelaksanaan Pembelajaran dengan pendekatan dan model pembelajaran daring; (g) Pelatihan dan pendampingan pembuatan Lembar Kerja Peserta Didik materi matematika berbasis teknologi; (h) Pelatihan dan pendampingan pembuatan desain pembelajaran daring melalui aplikasi Learning Managemen System dengan menarik dan bervariasi; (i) Pelatihan dan pendampingan dalam menggunakan aplikasi-aplikasi pembelajaran untuk pembelajaran matematika secara daring; (j) Pelatihan dan pendampingan merancang asesmen pembelajaran matematika berbantuan aplikasi-aplikasi pembelajaran; (k) Pendampingan pada pelaksanaan diskusi agar memperoleh feedback sehingga lebih terarah. Kegitan ini juga diharapkan memberikan stimulus positif melalui sharing satu dengan yang lain, sehingga bisa muncul inspirasi dan motivasi dalam 
pembelajaran daring. Partisipasi mitra dalam pelaksanaan kegiatan pengabdian sangat menentukan keberhasilan dan keberlanjutan program. Mitra berperan aktif dalam pelaksanaan kegiatan pengabdian.

\section{HASIL DAN PEMBAHASAN}

Kegiatan pengabdian dengan memberikan pelatihan pembelajaran daring matematika sekolah menengah diharapkan bisa meningkatkan kualitas guru matematika sekolah menengah dalam aplikasi matematika untuk menyelesaikan permasalahan matematika. Kegiatan ini memberikan manfaat bagi guru matematika sekolah menengah khususnya dalam melaksanakan pembelajaran matematika sekolah menengah secara daring, diantaranya yaitu: (a) guru dapat menyusun Rencana Pelaksanaan Pembelajaran dengan pendekatan dan model pembelajaran daring; (b) guru dapat membuat Lembar Kerja Peserta Didik materi matematika berbasis teknologi; (c) guru dapat mendesain pembelajaran daring melalui aplikasi Learning Managemen System dengan menarik dan bervariasi; (d) guru dapat menggunakan aplikasi-aplikasi pembelajaran untuk pembelajaran matematika secara daring, dan (e) guru dapat merancang asesmen pembelajaran matematika berbantuan aplikasi-aplikasi pembelajaran.

Kegiatan pelatihan ini mendapatkan tanggapan dan respon yang baik dan positif. Hal ini terbukti dari hasil pelaksanaan kegiatan ini dapat ditunjukkan dengan produk dari para guru matematika sekolah menengah berupa Rencana Pelaksanaan Pembelajaran Matematika sekolah menengah secara daring, Lembar Kerja Peserta Didik berbasis teknologi dan desain pembelajaran matematika secara daring menggunakan aplikasi Learning Managemen System, serta asesmen pembelajaran matematika mengunakan aplikasi-aplikasi pembelajaran. Beberapa faktor yang dapat mendukung keberhasilan kegiatan pelatihan ini, yaitu: (a) minat dan keinginan yang tinggi dari guru matematika dalam mengikuti kegiatan pelatihan ini sampai selesai; (b) ketertarikan dan dukungan dalam melaksanakan kegiatan pelatihan ini untuk lebih menguasai aplikasi-aplikasi pembelajaran; (c) adanya tanggapan dan respon yang positif, sehingga terjalin saling sharing wawasan ilmu tentang pembelajaran matematika secara daring, sehingga dapat mengembangkan kreativitas yang dimiliki untuk mengembangkan pembelajaran secara menarik dan interaktif, dan (d) Keterlibatan secara aktif saat pembuatan desain pembelajaran daring mencerminkan antusias dalam mengikuti kegiatan pelatihan tersebut. Selain itu, beberapa faktor yang dapat menghambat kelangsungan kegiatan pelatihan yaitu: penjadwalan pelaksanaan kegiatan pengabdian yang mundur beberapa bulan yang 
disebabkan oleh padatnya kegiatan guru matematika dan kurangnya koordinasi, sehingga menyebabkan kurangnya informasi yang diterima guru matematika dalam kegiatan pengabdian.

Kegiatan pengabdian masyarakat dengan pelatihan pembelajaran daring matematika sekolah menengah sangat bermanfaat dalam menambah wawasan pengetahuan pembelajaran berbasis teknologi terutama penggunaan aplikasi-aplikasi pembelajaran matematika. Materi kegiatan pengabdian masyarakat dalam memberikan pelatihan pembelajaran daring matematika sekolah menengah meliputi: pembuatan Rencana Pelaksanaan Pembelajaran secara daring, pembuatan bahan ajar berbasis teknologi, pembuatan Lembar Kerja Peserta Didik berbasis teknologi, pembuatan media pembelajaran daring, penggunaan aplikasi-aplikasi pembelajaran dan asesmen pembelajaran matematika secara daring.

Secara umum guru matematika merasa puas dan sangat merespon, yang tampak terlihat dari kesediaannya untuk mengikuti kegiatan-kegiatan pelatihan sehingga terlatih dan terbiasa dengan penggunaan aplikasi-aplikasi pembelajaran secara daring. Kegiatan pengabdian masyarakat dengan pelatihan pembelajaran daring matematika sekolah menengah menggunakan platform dan modul pelatihan untuk menunjang pelatihannya. Modul pelatihan pembelajaran daring memaparkan penggunaan aplikasi pembelajaran matematika merancang rencana pelaksanaan pembelajaran secara daring, yang diuraikan secara rinci baik penjelasan langkah dalam aplikasinya maupun contoh bahan ajarnya. Kegiatan pengabdian dengan pelatihan pembelajaran daring matematika sekolah menengah mendapat respon yang positif, hasil presentasi produknya yang berupa Rencana Pelaksanaan Pembelajaran, modul, Lembar Kerja Peserta Didik berbantuan aplikasi pembelajaran tercapai sangat baik. Begitu pula dengan aplikasi pembelajaran matematika berbasis teknologi juga tercapai dengan baik.

Penggunaan teknologi dalam pembelajaran matematika secara daring merupakan aktivitas dalam menggunakan aplikasi-aplikasi pembelajaran sehingga harus memiliki keberanian dan rasa percaya diri serta berwawasan luas. Apabila seseorang memiliki keterampilan dalam menggunakan aplikasi-aplikasi pembelajaran maka menumbuhkan kreativitas dan mengembangkan dalam dirinya. Untuk itu, pelatihan pembelajaran daring diharapkan bisa menambah rasa percaya dan keratif dalam mengaplikasikan teknologi dalam pembelajaran matematika. 


\section{KESIMPULAN DAN SARAN}

Hasil penelitian dan pembahasan yang telah dipaparkan, dapat disimpulkan yaitu: pelaksanaan kegiatan pelatihan berlangsung dengan baik sesuai dengan rencana dan jadwal yang ditentukan, pelaksanaan kegiatan pelatihan dinyatakan berhasil mencapai tujuan dan target yang ditetapkan, peserta kegiatan pelatihan termotivasi secara aktif dalam mengikuti kegiatan sampai tuntas, meningkatkan wawasan dan pengetahuan dalam aktivitas pembelajaran matematika sekolah menengah.

\section{DAFTAR PUSTAKA}

Atteh, E., Assan-Donkoh, I., Ayiku, F., Nkansah, E., \& Adams, A. K. (2020). The Use of Technology among School Mathematics Teachers and Students: The New Wave of Recommended Instructions. Asian Research Journal of Mathematics. https://doi.org/10.9734/arjom/2020/v16i530189

Belo, N., McKenney, S., Voogt, J., \& Bradley, B. (2016). Teacher knowledge for using technology to foster early literacy: A literature review. Computers in Human Behavior, 60. https://doi.org/10.1016/j.chb.2016.02.053

Cahyono, A. N., \& Ludwig, M. (2019). Teaching and learning mathematics around the city supported by the use of digital technology. Eurasia Journal of Mathematics, Science and Technology Education, 15(1). https://doi.org/10.29333/ejmste/99514

Carter, R. A., Rice, M., Yang, S., \& Jackson, H. A. (2020). Self-regulated learning in online learning environments: strategies for remote learning. Information and Learning Science, 121(5-6). https://doi.org/10.1108/ILS-04-2020-0114

Engelbrecht, J., Llinares, S., \& Borba, M. C. (2020). Transformation of the mathematics classroom with the internet. ZDM - Mathematics Education, 52(5). https://doi.org/10.1007/s11858-020-01176-4

Harris, D. N., \& Sass, T. R. (2011). Teacher training, teacher quality and student achievement. Journal of Public Economics, 95(7-8). https://doi.org/10.1016/j.jpubeco.2010.11.009

Keengwe, J., \& Georgina, D. (2012). The digital course training workshop for online learning and teaching. Education and Information Technologies, 17(4). https://doi.org/10.1007/s10639-011-9164-X

Loong, E. Y. K. (2014). Using the internet in high school mathematics. Journal on Mathematics Education, 5(2). https://doi.org/10.22342/jme.5.2.1496.108-126

Navarro-Ibarra, L., García-Santillán, A., Cuevas-Salazar, O., \& Ansaldo-Leyva, J. (2017). Mathematics, technology and learning: How to align these variables in order to explain anxiety towards mathematics and attitude towards the use of technology for learning mathematics. Eurasia Journal of Mathematics, Science and Technology Education, 13(9). https://doi.org/10.12973/eurasia.2017.01060a

Ruthven, K., Deaney, R., \& Hennessy, S. (2009). Using graphing software to teach about algebraic forms: A study of technology-supported practice in secondary-school mathematics. Educational Studies in Mathematics, 71(3). https://doi.org/10.1007/s10649-008-9176-7

Toropova, A., Johansson, S., \& Myrberg, E. (2019). The role of teacher characteristics for student achievement in mathematics and student perceptions of instructional quality. Education Inquiry, 10(4). https://doi.org/10.1080/20004508.2019.1591844 